\title{
Jaundice and Disseminated Intravascular Coagulopathy in Pregnancy
}

\author{
Robert Houston, MD, Jason Hayes, MD, Karen Wildman, MD, and
}

David Allerbeiligen, $M D$

Jaundice in pregnancy can be caused by viral hepatitis, intrahepatic cholestasis of pregnancy, choledocholithiases, HELLP syndrome (hemolysis, elevated liver enzymes, and a low platelet count), severe preeclampsia, and acute fatty liver of pregnancy. ${ }^{1}$ Acute fatty liver of pregnancy occurs in approximately 1 in 13,000 pregnancies. ${ }^{2}$ More than $90 \%$ of patients with acute fatty liver of pregnancy have jaundice and disseminated intravascular coagulopathy (DIC). ${ }^{3}$ Before 1985 the associated maternal mortality was reported as $85 \% .{ }^{4}$ Patients die with DIC, hemorrhage, severe hypoglycemia, and fulminant liver failure.

Acute fatty liver of pregnancy was first recognized as a distinct clinical syndrome in $1940 .^{5}$ The high maternal mortality initially associated with this condition was multifactorial, and in many cases the diagnosis was made at postmortem. Pregnancyrelated consumptive coagulopathy was not a recognized clinical entity until the 1950s. Furthermore, rapid serologic testing for infectious hepatitis was not readily available until the $1980 \mathrm{~s}^{6}{ }^{6}$ The historic management of hepatitis in pregnancy was conservative, and patients with undiagnosed acute fatty liver of pregnancy frequently progressed to fulminant liver failure and death.

Today early diagnosis of acute fatty liver of pregnancy and prompt delivery of the fetus is more commonplace. ${ }^{7}$ Rapid serologic testing for infectious hepatitis and DIC gives the modern clinician an edge in making the diagnosis. The following case has the classic clinical findings of acute fatty liver of pregnancy. The subsequent discussion provides an overview of this condition.

Submitted, revised 19 February 1999.

From the University of Wyoming Family Practice Program at Casper (BH, JH, KW, DA). Address reprint requests to Robert Houston, MD, University of Wyoming Family Practice Program at Casper, 1522 E. "A" Street, Casper, WY 82601 .

\section{Case Report}

A 38-year-old woman, gravida 4, para 3, at 38 weeks' gestation, complained on the evening of 17 April 1998 of a 3-day history of jaundice and a 1-day history of contractions, nausea, and diarrhea. The patient denied any recent exposure to ethanol, acetaminophen, or other hepatic toxins. She stated that a brother had died of acute hepatitis in the distant past. She denied fever, chills, right upper quadrant pain, dysuria, and headache. Her blood pressure was $115 / 73 \mathrm{~mm} \mathrm{Hg}$, heart rate 89 beats per minute, respirations $18 / \mathrm{min}$, and temperature was $98.6^{\circ} \mathrm{F}$. On examination the patient had icteric sclera and jaundiced skin. Findings of an examination of her heart and lungs were unremarkable. Her liver was nontender and her uterus had a $39-\mathrm{cm}$ fundal height. The fetus was vertex with normal cardiac activity. The patient's cervix was $3-\mathrm{cm}$ dilated, $50 \%$ effaced, and high. Rectal examination showed brown stool that was guaiac negative. Her lower extremities had a trace of edema, and her reflexes were normal.

Finding on a liver sonogram were normal except for a benign hepatic cyst. Her admission complete blood cell count showed a white blood cell count of $11,160 / \mu \mathrm{L}$, a hemoglobin of $12.3 \mathrm{~g} / \mathrm{dL}$, and a platelet count of $170,000 / \mu \mathrm{L}$. Her total bilirubin was 4.3 $\mathrm{mg} / \mathrm{dL}$, aspartate aminotransferase (AST) was 445 $\mathrm{U} / \mathrm{L}$, alanine aminotransferase (ALT) was 312 $\mathrm{U} / \mathrm{L}$, and her alkaline phosphatase was $380 \mathrm{U} / \mathrm{L}$. Her urinalysis and a urine drug-screening test were negative. Samples were drawn to determine acute infectious hepatitis A, B, and C titers. A follow-up complete blood cell count the next day was unchanged. Her liver studies worsened: total bilirubin was $5.9 \mathrm{mg} / \mathrm{dL}$, AST $520 \mathrm{U} / \mathrm{L}$, and ALT $334 \mathrm{U} / \mathrm{L}$. Bleeding studies were markedly abnormal: prothrombin time (PT) $14.4 \mathrm{sec}$, partial thromboplastin time, (PTT) $39.4 \mathrm{sec}$, and fibrin split products were $>40 \mu \mathrm{g} / \mathrm{mL}$. These findings were consistent with DIC. 
The patient's worsening liver function and a suspected diagnosis of acute fatty liver of pregnancy necessitated the delivery of her fetus. At 10:20 AM on 18 April 1998 artificial rupture of membranes was performed, and at 11:50 AM she gave birth to a 7-lb 3-oz. girl with Apgars of 8 and 10. After a manual extraction of the placenta, the patient hemorrhaged. Her acute bleeding was controlled with oxytocin, methylergonovine, and intravenous fluids. At 6:00 PM her PT had increased to $16.3 \mathrm{sec}$, PTT was $50.2 \mathrm{sec}$, and fibrin split products were $>40 \mu \mathrm{g} / \mathrm{mL}$; her hemoglobin decreased to 8.8 $\mathrm{g} / \mathrm{dL}$, and her platelet count was $142,000 / \mu \mathrm{L}$. Her white blood cell count increased to $20,970 / \mu \mathrm{L}$ with $80 \%$ neutrophils. She was given $2 \mathrm{U}$ of packed red blood cells and $2 \mathrm{U}$ of fresh frozen plasma. On 19 April 1998 her hemoglobin. was $9.8 \mathrm{~g} / \mathrm{dL}$ and her platelet count decreased to $110,000 / \mu \mathrm{L}$. Her PT was $14.9 \mathrm{sec}$, PTT was $48.6 \mathrm{sec}$, and fibrin split products remained $>40 \mu \mathrm{g} / \mathrm{mL}$. Her fibrinogen decreased from $174 \mathrm{mg} / \mathrm{dL}$ to $159 \mathrm{mg} / \mathrm{dL}$. The patient's persistent DIC was treated with 2 more units of fresh frozen plasma.

The patient's subsequent recovery was uneventful. She had a transient rise in her serum creatinine to $1.8 \mathrm{mg} / \mathrm{dL}$. Her edema resolved as her creatinine level returned to normal. Her fasting glucose level decreased to $68 \mathrm{mg} / \mathrm{dL}$ and $66 \mathrm{mg} / \mathrm{dL}$ in the postpartum period, but she denied hypoglycemic symptoms. Her viral hepatitis studies were negative. Results of her liver enzymes and bleeding studies returned to normal before discharge. A liver computed tomographic (CT) scan looking for acute fatty liver was not diagnostic. She was offered but refused a liver biopsy. When the patient was discharged on 22 April 1998, her hemoglobin was 9.1 $\mathrm{g} / \mathrm{dL}$, and she was given prenatal vitamins and iron.

\section{Discussion}

The common causes of jaundice in pregnancy are viral hepatitis, intrahepatic cholestasis of pregnancy, choledocholithiases, HELLP syndrome, severe preeclampsia, and acute fatty liver of pregnancy. ${ }^{7}$ Clinical jaundice with DIC is common only in acute fatty liver of pregnancy. ${ }^{8}$ DIC occurs in preeclampsia $7 \%$ of the time, in HELLP syndrome $30 \%$ of the time, and in acute fatty liver of pregnancy $90 \%$ of the time. ${ }^{2}$ Differentiating which of these three syndromes is causing the patient's jaundice and DIC can be difficult. ${ }^{9}$ Hypertension usu- ally precedes the DIC associated with preeclampsia and HELLP syndrome. Thrombocytopenia below $100,000 / \mu \mathrm{L}$ always occurs with HELLP syndrome. ${ }^{1}$ Most patients with acute fatty liver of pregnancy do not have hypertension or thrombocytopenia, but approximately $45 \%$ do have some findings of preeclampsia or HELLP syndrome. ${ }^{3}$

The pathophysiology of acute fatty liver of pregnancy is poorly understood. The diagnostic finding on liver biopsy is intrahepatic microdroplets of fat. ${ }^{10}$ These microdroplets contain free fatty acids with known cytotoxic properties. ${ }^{3}$ These liver biopsy findings are distinct from those found in preeclampsia and HELLP syndrome. ${ }^{11}$ Current research on acute fatty liver of pregnancy is focusing on maternal and fetal free fatty acid enzyme deficiencies. ${ }^{3}$ How these toxic free fatty acids are related to DIC and how they are quickly cleared with delivery of the fetus remain a mystery. We do know that the intravascular coagulopathy associated with acute fatty liver of pregnancy is linked to depressed antithrombin III levels. ${ }^{6}$

The average clinician is unlikely to suspect acute fatty liver of pregnancy. Many patients are admitted with a diagnosis of biliary tract disease, hepatitis, preeclampsia, or HELLP syndrome. ${ }^{5}$ These conditions in their mild forms can be treated with bed rest, and the appropriate treatment of acute fatty liver of pregnancy might be delayed. Jaundiced patients with elevated liver enzymes need to be tested for intravascular coagulopathy. When DIC is present and acute fatty liver of pregnancy is suspected, rapid delivery of the fetus is indicated. ${ }^{3}$ With delivery, the liver enzyme changes associated with acute fatty liver of pregnancy usually resolve in a few days. The patient's clinical course tends to follow a similar pattern. The coagulation abnormalities associated with acute fatty liver of pregnancy can take weeks to return to normal. ${ }^{6}$ These abnormal bleeding studies are usually not associated with a marked increased risk for maternal hemorrhage.

The family physician who cares for obstetric patients should recognize the hallmarks of acute fatty liver of pregnancy. Our patient had jaundice and mildly elevated liver enzymes. Our initial evaluation focused on cholelithiasis and infectious or drug-induced hepatitis. When the sonogram showed no evidence of cholelithiasis, and serologic tests for infectious hepatitis were negative, we ordered DIC laboratory studies. The patient's ele- 
vated PT, PTT, and fibrin split products raised our suspicion of acute fatty liver of pregnancy, HELLP syndrome, preeclampsia, and placental abruption. She was not hypertensive, she did not have thrombocytopenia, and she had no clinical evidence of abruption. The patient's other laboratory results were consistent with acute fatty liver of pregnancy: a leucocyte count of $>13,000 / \mu \mathrm{L}$, a mildly elevated serum creatinine level, mild hypoglycemia, and elevation in liver enzymes with the AST-ALT ratio $>1$. The patient's normal liver CT scan did not rule out acute fatty liver of pregnancy. CT scans have a high false-negative rate for acute fatty liver of pregnancy. ${ }^{12}$

When the family physician suspects acute fatty liver of pregnancy, delivery should be expeditious. Vaginal delivery should be attempted when possible because of the increased risk of maternal hemorrhage. When the fetus is thought not to be mature, the patient's cervix is unfavorable, or a prolonged labor is anticipated, delivery at a tertiary care center is probably advisable. The patient's coagulopathy was monitored closely during the 2 days after delivery, and clinical hemorrhage was treated with routine medications, intravenous fluids, packed red blood cells, and fresh frozen plasma. The prophylactic use of fresh frozen plasma or antithrombin III transfusions in asymptomatic patients has not been associated with any clinical benefit. ${ }^{6}$ Recognizing and aggressively treating maternal hypoglycemia in severe acute fatty liver of pregnancy might improve both fetal and maternal outcomes. ${ }^{3}$ Even though specific therapeutic interventions for acute fatty liver of pregnancy are limited, the early diagnosis and delivery for patients with acute fatty liver of pregnancy has been associated with reduced mortality. ${ }^{5}$

\section{References}

1. Creasy RK, Resnik R. Maternal fetal medicine: principles and practice. Philadelphia: WB Saunders, 1994.

2. Knox TA, Olans LB. Liver disease in pregnancy. N Engl J Med 1996;335:569-76.

3. de Swiet M. Medical disorders in obstetric practice. Oxford: Blackwell Scientific, 1989.

4. Kaplan MM. Acute fatty liver of pregnancy. N Engl J Med 1985;313:367-70.

5. Usta IM, Barton JR, Amon EA, Gonzalez A, Sibai $B M$. Acute fatty liver of pregnancy: an experience in the diagnosis and management of fourteen cases. Am J Obstet Gynecol 1994;171:1342-7.

6. Castro MA, Goodwin TM, Shaw KJ, Ouzounian JG, McGehee WG. Disseminated intravascular coagulation and antithrombin III depression in acute fatty liver of pregnancy. Am J Obstet Gynecol. 1996;174 (1 Pt 1): 211-6.

7. Danforth's obstetrics and gynecology. Philadelphia: JB Lippincott, 1994.

8. Holzback RT. Acute fatty liver of pregnancy with disseminated intravascular coagulation. Obstet Gynecol 1974;43:740-4.

9. Van Dam PA, Remier M, Baekelandt $M$, Buytaert P, Uyttenbroeck F. Disseminated intravascular coagulation and the syndrome of hemolysis, elevated liver enzymes, and low platelets in severe preeclampsia. Obstet Gynecol 1989;73:97-102.

10. Rolfes DB, Ishak KG. Acute fatty liver of pregnancy: a clinicopathologic study of 35 cases. Hepatology 1985;5:1149-58.

11. Barton JR, Riely CA, Adamec TA, Shanklin DR, Khoury AD, Sibai BM. Hepatic histopathologic condition does not correlate with laboratory abnormalities in HELLP syndrome (hemolysis, elevated liver enzymes, and low platelet count). Am J Obstet Gynecol 1992;167:1538-43.

12. Van Le L, Podrasky A. Computed tomographic and ultrasonographic findings in women with acute fatty liver of pregnancy. J Reprod Med 1990;35:815-7. 